\title{
Sócrates, Hadot e os exercícios espirituais
}

\section{Socrates, Hadot and the spiritual exercises}

Frank Alexandre Rosa Freitas ${ }^{1}$

\begin{abstract}
Resumo: O objetivo deste artigo é apontar a importância vital do diálogo socrático e, em especial, mostrar a figura de Sócrates na construção da tese dos exercícios espirituais de Pierre Hadot e a transformação/construção ética do sujeito ante a condição frágil e vulnerável do ser humano. Esse objetivo é aqui pensado a partir da interpretação que Hadot faz da figura de Sócrates e da filosofia antiga. Como problema filosófico e opção interpretativa diversa à visão de Hadot temos a questão de Vlastos, comparando o Sócrates mítico e o histórico. Com efeito, desde o início do pensamento grego, o Sábio aparece como uma norma viva e concreta como nota Hadot: "essas pesquisas, essas reflexões sobre o Sábio como norma se fixaram pouco a pouco, por muitas razões, na figura única de Sócrates". Sócrates torna-se o mediador entre o ideal transcendente de sabedoria e a realidade ética humana concreta.
\end{abstract}

Palavras-chave: Filosofia antiga. Hadot. Sócrates.

Abstract: The aim of this article is to point out the vital importance of Socratic dialogue and, in particular, in the figure of Socrates in the construction of Pierre Hadot's thesis of spiritual exercises and the transformation/ethical construction of the subject in the face of the fragile and vulnerable condition of the human being. This goal is thought here from Hadot's interpretation of the figure of Socrates and ancient philosophy. As a philosophical problem and interpretive option different from Hadot's view we have the question of Vlastos, comparing the mythical Socrates and the historical. Indeed, from the beginning of Greek thought, the Sage appears as a living and concrete norm as Hadot notes: "these researches, these reflections on the Sage as the norm have gradually settled, for many reasons, in the unique figure of Socrates". Socrates becomes the mediator between the transcendent ideal of wisdom and concrete human ethical reality.

Keywords: Hadot. Socrates. Spiritual Exercises.

\section{Introdução}

Pierre Hadot é considerado um dos grandes historiadores da filosofia antiga e possui uma admirável fascinação pela figura de Sócrates desenhada por Platão, especialmente nos

\footnotetext{
${ }^{1}$ Graduado em Filosofia (Licenciatura e Bacharelado) pela Universidade Federal do Pará. Especialista em Filosofia da Educação pelo Instituto de Ciências da Educação/UFPA. Mestre pelo Programa de Pós-Graduação em Filosofia/UFPA. Professor do Ensino Médio/SEDUC-PA. Participante e pesquisador do grupo de pesquisa "Hermenêutica, Antropologia e Educação" da Universidade Federal do Pará. Participante e pesquisador do projeto de pesquisa "Sujeito, História e Poder: Michel Foucault, leitor de Nietzsche". Participante e pesquisador do Grupo de Pesquisa "Filosofia Contemporânea" da Universidade Federal do Pará. Participante e pesquisador no grupo de pesquisa "Paideia - Filosofia da Educação, epistemologia e Formação" da Universidade Federal do Pará. Email: professorfzr@gmail.com. Artigo recebido em 31/03/2020 e aceito em 13/04/2020.

Perspectivas - Revista do Programa de Pós-Graduação em Filosofia da UFT - volume 5, n. 1 - 2020
} 
chamados "diálogos socráticos" e principalmente a partir da máscara socrática construída por Platão no diálogo $O$ Banquete. Não se trata, portanto, da figura histórica, mas daquela idealizada e imortalizada por seu discípulo mais famoso. Para apresentar contraditório e dilemas na interpretação de Hadot optei por mostrar, brevemente, a interpretação diversa de Vlastos, de orientação analítica, para problematizar a figura de Sócrates em Hadot.

Para Hadot, é extremamente difícil distinguir a parte socrática e a parte platônica nos diálogos. Para Vlastos, tal distinção deve ser feita, apesar de concordar com Hadot quanto a extrema dificuldade de distinção. Para Hadot, Sócrates “aparece, assim, pouco tempo após a sua morte, como uma figura mítica" (HADOT, 1999, p. 49). Todavia, foi desse ser mitológico, as vezes sobre a máscara de Éros, outras sobre a máscara de um Sileno, que Pierre Hadot vai eleger como a figura chave da sua interpretação da filosofia antiga como modo de vida e exercício espiritual.

\section{Desenvolvimento}

\subsection{Pierre Hadot, e os Exercícios Espirituais}

Para Hadot, ao analisar a filosofia praticada na antiguidade, percebemos que todas possuem não só um caráter espiritual comum, mas também um caráter histórico. Hadot pensa que, recuperando a concepção espiritual antiga da filosofia podemos descobrir uma história das atitudes filosóficas fundamentais e de suas diversas opções existenciais. Seu projeto se foca no objetivo de escrever uma história da filosofia que integre esta dimensão existencial vivida ao estudo das doutrinas e reconstrução do discurso filosófico. Oferecer outro conceito possível de filosofia em nossos dias parece ser o objetivo dele, recuperando a ideia de filosofia como uma atividade de vida, buscando reencontrar a tradição em que a filosofia se definia como exercícios espirituais e forma de vida. O historiador da filosofia afirma em seus escritos que a filosofia na antiguidade consistia em um exercício espiritual ${ }^{2}$ a prática destes exercícios era designada pelo termo grego áskesis, que denominavam e correspondiam a um trabalho de modificação do indivíduo sobre si mesmo e sobre sua visão de mundo. As teorias filosóficas da antiguidade,

\footnotetext{
2 "Para mim, foi um texto de Bergson, tema da minha dissertação do meu exame de 1939 de conclusão do ensino médio, em que foi proposto um texto de Bergson: 'A filosofia não é uma construção de sistema, mas a resolução, uma vez tomada [ou seja, tomada de uma vez por todas], de olhar ingenuamente para dentro de si e em torno de si'. Primeiramente, a formulação 'a filosofia não é uma construção de sistema' eliminava de saída toda a construção teórica e abstrata. Depois tinha a segunda parte da frase, que significava que a filosofia é antes de tudo uma escolha, não um discurso. Era uma decisão, uma atitude, um comportamento, uma maneira de ver o mundo". (HADOT, 2016, p. 158).

Perspectivas - Revista do Programa de Pós-Graduação em Filosofia da UFT - volume 5, n. 1 - 2020
} 
mais precisamente as desenvolvidas a partir de Sócrates, estão intrinsicamente ligadas a uma escolha sobre determinados estilos de vida. Esse caráter pode ser entendido como uma opção existencial, uma maneira de ser e agir sobre si mesmo e os outros circundantes. Esse modo de vida é segundo ele, inicial e não final, uma vez que o discurso filosófico tem origem nestes respectivos estilos de vida e não o contrário, afinal, sua ação prática é revelar de maneira racional estas visões de mundo. Portanto, o filósofo na antiguidade, caracteriza-se tanto pelo discurso racional que aplica, quanto pelo modo de vida que pratica.

O significado da filosofia enquanto discurso e prática de vida não poderia ser compreendido fora deste horizonte. Elas estavam, de certa maneira, inscritas na prática espiritual, que levava a uma perspectiva concreta, "a ideia da filosofia como transformação da percepção". ${ }^{3}$ Haveria uma característica comum nas escolas ${ }^{4}$ de filosofia antiga, subjacente às suas construções teóricas, a qual se teria de ter em vista nossa aproximação destas:

O discurso filosófico tem sua origem, portanto, em uma escolha de vida e em uma opção existencial, e não ao contrário. Em segundo lugar, essa decisão e essa escolha jamais se fazem na solidão: nunca houve filosofia nem filósofos fora de um grupo, de uma comunidade, em uma palavra, de uma 'escola' filosófica; e, precisamente, uma escola filosófica corresponde, nesse caso e antes de tudo, a maneira de viver, a uma escolha de vida, a uma opção existencial, que exige do indivíduo uma mudança total de vida, uma conversão de todo o ser, e, finalmente, a um desejo de ser e de viver de certa maneira (HADOT, 1999, p. 17-18).

Levemos em consideração que Hadot ressalta, ao investigar a obra de uma escola filosófica ou a de um filósofo antigo, a situação específica no qual ela se desenvolveu. As obras “de cada escola têm seu método terapêutico próprio, mas todos ligam a terapêutica a uma transformação profunda da maneira de ver e de ser do indivíduo. Os exercícios espirituais terão precisamente como objetivo a realização dessa transformação" (HADOT, 2014, p. 23). Neste caso seriam os produtos de uma escola filosófica, no sentido mais concreto do termo, no qual um mestre forma seus discípulos, tentando guia-los à auto formação. A filosofia antiga na sua forma original levava em conta essa perspectiva:

\footnotetext{
${ }^{3}$ Idem, ibidem, p. 159.

${ }^{4}$ Em $O$ que é Filosofia Antiga? A ideia de escola parece ter um papel importantíssimo na definição da filosofia antiga. Ao empregar a noção de escola para explicar a relação entre uma escolha de forma de vida e o discurso, no âmbito das relações com o outro e consigo mesmo de alteridades que formam o núcleo da filosofia antiga ao privilegiar a integração das doutrinas filosóficas com as práticas de vida. Dessa forma as escolas são o meio privilegiado onde as práticas e as circunstancias concretas de vida fazem o indivíduo problematizar certos aspectos de si mesmo, levando a uma reflexão sobre si e sobre os outros. Na mesma linha de pensamento está Frederico Testa quando escreve em seu artigo: "Es entendiendo la escuela como instancia concreta y colectiva de la vida filosófica que podemos entender los textos y los contenides particulares de las diferentes doctrinas filosófocas. El concepto de Hadot de 'escuela' podría guiarnos en una história de prácticas filosóficas concretas” (TESTA, 2017, p. 179-199).
}

Perspectivas - Revista do Programa de Pós-Graduação em Filosofia da UFT - volume 5, n. 1 - 2020 
O que eu disse de uma maneira geral em meus livros sobre os exercícios espirituais poderia dar a impressão, embora eu tenha tentado evitá-la, de que os exercícios espirituais são algo que se acrescenta à teoria filosófica, ao discurso filosófico: seria apenas uma prática que completaria a teoria e o discurso abstrato. Na realidade, é a filosofia em sua inteireza que é exercício, tanto o discurso de ensino quanto o discurso interior que orienta nossa ação [...] o que eu quis mostrar em especial foi justamente que aquilo que consideramos como pura teoria, como abstração, era prático (HADOT, 2016, p. 116).

Assim, os exercícios espirituais não seriam uma construção teórica apenas, mas um método para a formação de pessoas para viver a filosofia lançando um olhar para si mesmo e para o mundo de uma maneira nova. Nas obras acima referidas, Pierre Hadot expôs uma concepção de filosofia antiga em que expressa claramente essa ideia. Nota-se que sua tese se opõe à visão moderna sobre o que seria a filosofia antiga, na medida em que nosso modo de ver e entender a filosofia antiga nos leva a conceber o saber nos dias atuais como algo a ser encontrado nas práticas teóricas, sendo a função do filósofo teorizar abstratamente, sem ter importância o estilo de vida que adote. A ideia principal de filosofia abordada por Hadot, cujas origens estão situadas na antiguidade grega, é a formação dos indivíduos, ou mais precisamente do espirito dos alunos das diferentes escolas filosóficas, de modo que estes exercitem a formação de si mediante o uso do discurso filosófico unido a um modo de vida que transforme o ser mesmo dele, ao estar em harmonia com a razão. De uma maneira geral os preceitos dessa concepção identificada pelo filósofo historiador estiveram presentes ao longo de todas as escolas filosóficas da antiguidade estudadas por ele. Principalmente o platonismo e o estoicismo.

\subsection{A importância da figura de Sócrates na filosofia como "exercício espiritual” em Hadot}

Ao mergulharmos no universo conceitual e interpretativo de Hadot sobre o que é a filosofia praticada na antiguidade, percebemos que todas possuem um traço espiritual em comum. Para o historiador da filosofia interpretar o modo de pensar antigo levando em conta essa perspectiva significa devolver ou retornar a filosofia em seu estado original e entendida de acordo com a distinção entre a prática vital das virtudes e o discurso segundo a filosofia, no sentindo mais concreto do termo, no qual um mestre cuida dos seus discípulos levando-os à autotransformação que seria a articulação entre a prática da filosofia e o discurso filosófico. Tal perspectiva nos permite compreender a forma pela qual Platão e Sócrates entendiam a articulação entre discurso filosófico e prática de vida, que irá ecoar na filosofia do período helenístico-romano: 
A palavra philo-sophia, 'amor pela sabedoria', bastava, aos olhos antigos, para exprimir essa concepção de filosofia. Platão, no Banquete havia mostrado que Sócrates, figura do filósofo, podia ser identificado a Eros, filho de Poros (expediente) e de Penia (pobreza). Ele estava privado da sabedoria, mas sabia busca-lo. A filosofia parecia assim um exercício do pensamento, da vontade, de todo o ser, para tentar chegar a um estado, a sabedoria, que era, aliás, quase inacessível ao homem. A filosofia era um método de progresso espiritual que exigia uma conversão radical, uma transformação radical da maneira de ser. Maneira de viver, a filosofia o era então o esforço, no seu exercício, para alcançar a sabedoria, mas também era um objetivo, a própria sabedoria, pois a sabedoria não faz somente que possamos conhecer, mas faz 'ser' diferentemente (HADOT, 2014, p. 262-263).

A partir de Sócrates, Hadot considera que as teorias filosóficas da antiguidade estão intimamente ligadas a um estilo, a uma determinada opção existencial. A filosofia seria uma escolha por um determinado modo de vida, uma maneira de ser perante os outros e a si mesmo, revelando de maneira racional essas visões do mundo, não se reduziria à elaboração de discursos que visam à sistematização de conceitos, estando, ao contrário, estreitamente vinculada ao exercício de um determinado modo de vida, que, geralmente, se opunha ao modo de vida não filosófico. Com Sócrates, os exercícios espirituais teriam surgido na filosofia ocidental $^{5}$, e teriam se fixado em nossa consciência, permanecendo ele com a imagem daquele que nos chama a acordar a nossa consciência. Essa opção existencial é segundo Hadot, inicial e não final, ou seja, os modos de vida dão origem aos discursos filosóficos e não ao contrário ${ }^{6}$. A forma através da qual chegamos a isso é para Sócrates o diálogo, o qual seria uma forma de exercício espiritual, ao encaminhar os seus interlocutores a uma transformação, conversão, que para efetivar-se, necessitava da aceitação destes. Nesta busca pela verdade, os interlocutores precisavam aceitar tomar parte nesse jogo ascético na medida que aceitavam ser transformados:

Trata-se menos de questionar o saber aparente que se acredita possuir do que questionar a si mesmo e os valores que dirigem nossa própria vida. No fim das contas, após ter dialogado com Sócrates, seu interlocutor já não sabe muito bem por que age [...], mas fazendo isso, toma distância em relação a si mesmo, desdobrando-se, uma parte de si mesmo identificando-se, de agora em diante, com Sócrates no acordo mútuo que este exige de seu interlocutor em cada etapa da discussão. Opera-se nele uma tomada de consciência de si; ele se põe a si mesmo em questão (HADOT, 1999, p. 55-56).

Embora para Hadot seja difícil determinar o sentido da expressão "conhece-te a si mesmo" daquela época, ao falar sobre esse preceito é impossível não destacar o aspecto de uma

\footnotetext{
${ }^{5}$ Para Hadot, as práticas de exercícios espirituais possuem uma temporalidade muito antiga e provavelmente irrastreáveis,

${ }^{6}$ Segundo Hadot, muitos historiadores da filosofia atribuem certas contradições lógicas nos textos filosóficos antigos porque partem da premissa de que tanto na Antiguidade quanto na Modernidade os textos filosóficos estariam vinculados a um sistema conceitual de produção discursiva estritamente coerente e lógico em sua estrutura interna.
}

Perspectivas - Revista do Programa de Pós-Graduação em Filosofia da UFT - volume 5, n. 1 - 2020 
relação consigo mesmo. Ora, a relação consigo mesmo é para o historiador da filosofia o fundamento de todo exercício espiritual. Portanto, os antigos discursos filosóficos podem parecer contraditórios aos leitores que não compreendem o texto no contexto teleológico no qual os diferentes gêneros literários da antiguidade se inseriram.

\subsection{O Banquete na apresentação do Sócrates mítico em Hadot e as divergências com o Sócrates histórico em Vlastos}

Escrever diálogos onde Sócrates é protagonista é característico do gênero literário chamado logos socráticos, gênero este surgido após a morte de Sócrates, no qual Platão não apenas faz de Sócrates o personagem central dos seus diálogos, mas representa-lo como o modelo da virtude. A diferença entre o Sócrates idealizado e o Sócrates histórico vai levantar um sério problema filosófico entre os filósofos especialistas em filosofia antiga. Par Pierre Hadot este modelo ideal de fazer filosofia é iniciado no diálogo Banquete. No referido dialogo, Alcibíades elogia sua moderação $(217 \mathrm{a}-219 \mathrm{e})$, sua tolerância ao frio e à fome, bem como ao álcool em excesso (219e - 220b), e sobretudo sua coragem em campo de batalha (220c - 221c). Em seu elogio de Sócrates, Alcibíades insiste que não podemos compará-lo a nenhum homem, somente aos Silenos e aos Sátiros (215b). "O que tentarei apresentar-lhes agora é a figura de Sócrates tal como ela agiu na nossa tradição ocidental, a figura de Sócrates tal qual aparece no Banquete de Platão" (HADOT, 2014, p. 92).

Platão, que fora influenciado pela personalidade de Sócrates, deu um novo sentido a palavra "filosofia". Em realidade, mesmo quando a filosofia não se apresenta em forma de diálogo estava implícito esse modelo, pois as cartas, as consolações e os cadernos de nota possuíam, junto com os diálogos, ao mesmo tempo uma influência política, uma dimensão terapêutica - que aproximava a filosofia da medicina- e uma estrutura que visava fundamentar a escolha por um estilo de vida virtuoso. Trata-se bem menos de questionar o saber aparente que se acreditava possuir do que questionar a si mesmo e os valores que dirigem a nossa própria vida. No fim das contas, após ter dialogado com Sócrates, seu interlocutor já não sabe muito bem porque age. Ele toma consciência das contradições do seu discurso e das próprias contradições internas.

A figura mítica/histórica de Sócrates exemplifica bem essa visão da filosofia antiga, ao se apresentar como aquele que nada sabe ele está implicitamente lembrando os outros que o saber não possui apenas uma dimensão teórica rigorosa cujas proposições e conteúdos podem analiticamente serem transmitidas. Isso fica claro na passagem do Banquete: 
175 D -vem para cá, Sócrates-, lhe falou Agatão; -reclina-te ao meu lado, para que, em contato contigo, eu também frua do pensamento excelso que te ocorreu no pórtico. Sem dúvida encontraste o que procuravas e o seguraste com firmeza, sem o que não te houveras arredado do lugar-

Depois de sentar-se, dissera Sócrates: -seria bom, Agatão, lhe falou, -se com a sabedoria acontecesse isso mesmo: pela simples ação de contato, passar de quem tem muito para quem está vazio, tal como se dá com a água, que escorre por um fio de lã, da copa cheia para a que tem menos. Se com a sabedoria acontecer a mesma coisa, para mim será de suma importância ficar junto de ti, pois espero saturar-me à custa de tua abundante e excelente sabedoria. A minha é fraquinha e duvidosa como os sonhos; a tua, pelo contrário, brilhante e promissora, pois, apesar de seres moço, irradia-se com tal força, que ainda anteontem luziu na presença de trinta mil helenos (PLATÃO, 2011, p. 83).

Entretanto, Vlastos ${ }^{7}$, em The historical Socrates and Athenian Democracy ${ }^{8}$, serve como contraponto para o pensamento de Hadot ao sinalizar a importância do Sócrates histórico para o ideal filosófico. Construindo um debate de orientação analítico e filosófico, adotando uma forma de expressão clara, direta, muito concisa e eloquente, que combina analises conceituais com a solidez do logica, laçando um debate interessante com o filósofo francês. Apesar da rica figuração na qual o Sócrates de Hadot é envolto, a imagem proposta pelo autor francês claramente privilegia a versão platônica e em princípio não foge aos discursões frequentes nos analíticos sobre o socratismo na forma que ainda hoje eles assumem.

Em sua obra, acima mencionada, Vlastos argumenta a favor da tese de que o Sócrates histórico deveria ser entendido em sua relação com a cidade, a partir do exame de várias fontes disponíveis que ele considera sólidas e adequadas para considerar os pontos com as quais se propõe tratar, sem se limitar a escolher, como foi feito por Hadot, entre os principais testemunhos disponíveis (os de Xenofonte, Aristófanes ou Platão) e, a partir dessa escolha, defende de sua própria posição. Ou seja, diferente de Hadot, Vlastos considera as três fontes para apoiar seus argumentos sobre o Sócrates histórico, enquanto Hadot se apoia no Sócrates idealizado por Platão, a partir do Banquete. Vlastos afasta-se do caminho seguido por Hadot.

Outra diferença crucial na abordagem sobre a questão de qual Sócrates deve ser privilegiado, se o histórico ou mítico, é a abordagem de ambos os autores sobre a ironia socrática. Para Hadot, o jogo de ocultar-se atrás da máscara socrática revela a ironia platônica. Todavia, algo que chama a atenção de Hadot é o fato de Sócrates também se mascarar nos diálogos platônicos. Assim no texto chamado de A figura de Sócrates, Hadot apresenta o filósofo sob três máscaras, das quais uma é brevemente apresentada aqui: de Eros. A máscara,

\footnotetext{
${ }^{7}$ Gregory Vlastos foi um estudioso da filosofia antiga e autor de vários trabalhos sobre Platão e Sócrates. Ele é considerado um estudioso proeminente de Sócrates que transformou a análise da filosofia clássica.

8 Trabalho publicado na revista Political Theory (1983).

Perspectivas - Revista do Programa de Pós-Graduação em Filosofia da UFT - volume 5, n. 1 - 2020
} 
de Eros, pode ser considerada o vértice da ironia socrática, ao apresentar duas questões fundamentais para os exercícios espirituais, a dimensão vivida e viva da atividade filosófica. Essa máscara do qual o filosofo francês fala é aquela apresentada no referido dialogo socrático. Para Vlastos, no primeiro intitulado Socrates, Ironist and Philosopher ${ }^{9}$, explora, de modo diferente, o sentido do termo ironia presente em Sócrates, em especial no que tange à identificação do famoso estilo irônico em Sócrates pelo famoso estilo socrático: "não muda a palavra ao teorizar sobre ela, mas cria algo novo para ela exprimir uma nova forma de vida que em si mesma era percebida como a própria encarnação da ironia, segundo o uso contemporâneo"10. Ao analisarmos a estratégia de Vlastos, ao analisar a figura de Sócrates, logo percebemos que a pergunta “quem foi Sócrates?” Polemiza com a resposta de Hadot. Em outras palavras, o Sócrates idealizado por Platão no Banquete é diferente do Sócrates histórico. São visões diferentes, porem que levam a questões complexas, que poderão ser tratadas em outro artigo. Acredito, que como ambos os autores percebem a questão da ironia em Sócrates expõem bem seus métodos sobre a figura de Sócrates.

Para Hadot, é a famosa ironia socrática que leva os interlocutores a descobrir que nada sabem ao serem interrogados sobre o que efetivamente sabem, ao julgarem saber efetivamente algo, Sócrates demonstrava a intenção de aprender com eles, todavia, com o decorrer do diálogo o interlocutor mesmo descobre, levado por Sócrates, que nada sabe. Portanto:

A missão de Sócrates é fazer que os homens tomem consciência de seu não
saber. Trata-se aqui de uma revolução na concepção de saber. Sem dúvida,
Sócrates pode dirigir-se a estranhos, e o faz com prazer, dizendo-lhes que têm
apenas um saber convencional, que só agem sob a influência de preceitos sem
fundamento refletido, para mostrar-lhes que seu pretenso saber não repousa
sobre nada (HADOT, 1999, p. 52).

Para Vlastos, a famosa ironia socrática não se manifesta claramente. Por exemplo, no Sócrates de Xenofonte ${ }^{11}$ difere do Sócrates platônico. E mesmo o Sócrates platônico é diferente nos diálogos de maturidade e nos diálogos de juventude ${ }^{12}$. A tese principal é a de que o Sócrates dos primeiros diálogos é mais fiel ao histórico, em contraposição com aquele presente nos diálogos da maturidade. Vlastos percebe que a ironia é muito forte nos diálogos de juventude em Platão e, portanto, o personagem principal dos diálogos platônicos nesse período é o Sócrates histórico. Já o Sócrates presente nos diálogos de maturidade é o Sócrates idealizado por Platão.

\footnotetext{
${ }^{9}$ VLASTOS, 1991.

${ }^{10}$ VLASTOS, 1991, p. 29.

11 VLASTOS, 1991, p. 31.

12 VLASTOS, 1991. Desenvolvido pelo autor no capítulo "Sócrates contra Sócrates em Platão. Perspectivas - Revista do Programa de Pós-Graduação em Filosofia da UFT - volume 5, n. 1 - 2020
} 
A dificuldade para realizar as divergências entre as interpretações entre Hadot e Vlastos é visível. Porém, o problema levantado é relevante para a compreensão da figura de socastes e seu papel na filosofia ocidental. Creio que na visão de Vlastos Hadot generaliza o Sócrates presente no Banquete, enquanto Hadot não foca no Sócrates histórico "devemos nos deter longamente não no Sócrates histórico, dificilmente cognoscível, mas na figura mítica de Sócrates tal qual apresentada pela primeira geração de seus discípulos” (HADOT, 1999, p. 47).

\subsection{A influência de Sócrates no período helenístico e romano em Hadot}

Embora a figura de Sócrates tenha ocupado Hadot quase com a mesma frequência e intensidade que Marco Aurélio, Sêneca, Plotino Epiteto, etc. ela é um dos componentes fundamentais de sua tese maior sobre a filosofia antiga. Com efeito, a figura de Sócrates representa ao mesmo tempo a atitude filosófica e o marco histórico fundadores desta concepção de filosofia. Hadot afirma que para o pensamento atual sobre o que é filosofia antiga, a mesma aparece frequentemente como pouco sistemática, com a característica de não possuir uma ordem, um rigor linear. O historiador da filosofia se refere, então, a Bergson, ao lembrar que, em 1939, por ocasião do seu exame "de conclusão de seu ensino médio, em que o tema proposto foi um texto de Bergson: 'a filosofia não é uma construção de sistema, mas a resolução, uma vez tomada [ou seja, tomada de uma vez por todas], de olhar ingenuamente para dentro de si' [...]", o levou a concluir que "o essencial no bergsonismo será sempre, a meu ver, a ideia da filosofia como transformação da percepção" (HADOT, 2016, p. 158-159). A tese de exercício espiritual, em suma, pode ser definida como uma prática voluntaria, pessoal, destinada a operar uma transformação do indivíduo, uma transformação de si. A maneira de viver filosoficamente é simplesmente o comportamento do filósofo na vida quotidiana. Em outros termos, trata-se do comportamento característico de cada escola filosófica posterior a morte de Sócrates no período helenístico e romano.

Por exemplo, mesmo a dimensão textual, presente em Aristóteles, cujos escritos, que comumente são encarados como tratados expositivos de sua doutrina, não serviriam, segundo Hadot, apenas para demonstrar um sistema completo de suas doutrinas. Sobre isso, ele afirma:

Isso é muito importante, a meu ver, porque o que eu quis mostrar em especial foi justamente que aquilo que consideramos como pura teoria, como abstração, era prático tanto em seu modo de exposição quanto em sua finalidade. Quando Platão compõe seus diálogos, quando Aristóteles ministra seus cursos e publica suas anotações de aula, quando Epicuro redige suas cartas ou mesmo seu tratado sobre a natureza", desse modo haveria em Aristóteles uma espécie de treinamento para os seus discípulos na técnica de 
utilização de métodos corretos na lógica, nas ciências naturais e na ética. Esse treinamento é um exercício espiritual na medida que ele teria sido melhor em criar perguntas abordadas a partir de visões diferentes, o que produziria respostas incoerentes entre si, "em Aristóteles isso é muito característico - não se responde à pergunta de imediato, muitas voltas são dadas para proporcionar a resposta (HADOT, 2016, p. 216-217).

Perguntar incessantemente é sempre melhor do que fornecer respostas. Seguindo a narrativa de Hadot na referida entrevista a Arnold I. Davidson, podemos inferir, guardadas as devidas diferenças entre elas, que a descrição da filosofia de Aristóteles se estenderia a quase todas as escolas de filosofia antigas. Afirmamos que essa característica apontada por Hadot aproxima a filosofia antiga de um exercício dialético ${ }^{13}$ e a afastaria de proposições de sistemas unitários rígidos. Está evidente que, para o historiador, a filosofia antiga não se reduz à elaboração que visa a sistematização de conceitos, mesmo em Aristóteles é possível perceber que a filosofia estava muito particularmente vinculada ao exercício de um determinado modo de ser e viver. O filósofo é apenas um instrumento que proporciona e auxilia o outro a operar essa descoberta interior, a partir de valores, e não somente a partir de conceitos. Assim, o continuo exame de si, através dos exercícios espirituais orientado pelo filósofo, tem por meta atingir a pureza da intenção e ação moral. Os diálogos, cartas e cadernos de notas possuíam uma dimensão política e terapêutica aliado a um aporte teórico que visava fundamentar um estilo de vida virtuosamente moral.

Esses exercícios são segundo o historiador melhor notados no período helenístico e romano ao citar o exemplo dos estoicos. A filosofia no período helenístico foi muito marcada pelo espírito socrático ${ }^{14}$ e com a Stoa de Zenão não foi diferente. Nos estoicos, a filosofia era certamente entendida como exercício, não como conhecimento ou interpretação de textos, mas como uma arte de viver, uma atitude que leva a um estilo de vida no ato filosófico que põe em movimento todo o ser do sujeito ao modificar sua vida e ao realizar essa modificação o ato filosófico não seria para esse filosofo apenas um ato intelectivo, mas poria em xeque toda a sua existência, o modo de ser do sujeito. Portanto, a filosofia teria o papel de terapêutica.

\footnotetext{
${ }^{13}$ Tradicionalmente, em sentido bastante genérico, o termo dialético é entendido como exercício de discussão de uma determinada tese, foi amplamente ensinada na Academia de Platão através de um processo de diálogo, debate entre os interlocutores comprometidos com a busca da verdade, através do qual a alma se eleva, gradativamente das aparências sensíveis às realidades inteligíveis. Ao escapar das armadilhas do interlocutor o objetivo era que cada qual dos interlocutores funde seus argumentos em torno do que o outro reconhece saber, superando os pontos de vista particulares atinge-se o universal baseado num saber compartilhado. Nesse sentido trata-se de um exercício espiritual mútuo, que leva a uma transformação deles mesmos através de uma ascese: "como em toda a filosofia antiga, a filosofia consiste aqui no movimento pelo qual o indivíduo se transcende em alguma coisa que o supera, para Platão, nos logos, no discurso que implica uma exigência de racionalidade e de universalidade" (HADOT, 1999, p. 100).

${ }^{14}$ As quatros principais escolas em Atenas eram: a Academia de Platão, o Liceu de Aristóteles, o Jardim de Epicuro e a Stoa de Zenão. Todas sofreram influencias de filosofia de Sócrates.

Perspectivas - Revista do Programa de Pós-Graduação em Filosofia da UFT - volume 5, n. 1 - 2020
} 


\section{Conclusão}

Para Hadot, os textos antigos não possuem a característica de um sistema conceitual, mesmo em Aristóteles, pois, diferentemente dos textos modernos, eles possuíam uma dimensão oral e um caráter prático. Nesse sentido, as filosofias seriam uma espécie de terapêutica das paixões, pois estas eram consideradas os motivos do sofrimento humano, pelos medos e desejos que as paixões da alma traziam. Ao transformar o sujeito, os exercícios espirituais objetivariam levar o indivíduo a alcançar a libertação das paixões. Esta concepção filosófica estaria presente em todas as filosofias gregas, helenísticas e romanas, em todas elas o conhecimento teórico nunca é desvinculado da prática, apesar de cada uma possuir sua própria terapêutica. De qualquer maneira, Hadot explica que os textos antigos dessas escolas não eram um simples sistema conceitual, por possuírem um caráter terapêutico e prático. Portanto, o conhecimento teórico vinculado a prática, leva a uma terapêutica. Segundo Ortega:

Hadot resume toda a filosofia antiga em relação aos exercícios espirituais, os quais são a expressão de um esforço que não aspira a transmitir informação sobre teorias abstratas, mas antes a formar as almas dos alunos. O objetivo dos exercícios espirituais é formar em vez de informar; não se trata de uma construção teórica, mas de um exercício de formação de si, da Paideia que ensina a viver em harmonia com a razão. Esta noção de filosofia forma uma constante em todas as escolas filosóficas da Antiguidade greco-latina - dos platônicos aos estoicos. A matemática para os platônicos, os três topoi para Marco Aurélio - a física como disciplinamento do desejo, a ética como disciplinamento das inclinações e a lógica como disciplinamento do juízo constituem importantes exercícios espirituais, pois permitem identificar a mirada da alma e a mirada divina e tentam oferecer uma regra de existência que possa estar a mão em qualquer circunstância e que permita resolver os problemas que a vida apresenta a cada instante. Até mesmo o próprio conhecimento representa um exercício espiritual para Platão e Plotino. Todas as doutrinas filosóficas concordam em que até o tratado mais sistemático aspira a fomentar o processo espiritual do aluno: formação em vez de transmissão de informação (ORTEGA, 1999, p. 52-53).

Para Hadot, muitos historiadores da filosofia antiga atribuem contradição aos textos dos filósofos antigos, porque partem do postulado de que tanto na antiguidade quanto na Modernidade a filosofia se ligaria a um discurso que constituiria, por sua vez, um sistema conceitual e logicamente coerente nas suas articulações internas, não levando em consideração o seu caráter terapêutico. Nos estoicos, por exemplo, essa tarefa de formação da filosofia consistia em educar os homens a não desejar nada além do que está em seu poder obter, possuía um conteúdo prioritariamente prático, já que eles propunham exercícios para alunos com o a preocupação de solucionar efetivamente os problemas decorrentes das paixões de seus espíritos: 
Para todas as escolas filosóficas, a principal causa de sofrimento, desordem, inconsciência para o homem são as paixões: desejos desordenados, medos exagerados. A supremacia da preocupação impede de viver verdadeiramente. A filosofia aparecerá então, em primeiro lugar, como uma terapêutica das paixões ('Esforçar-se para despojar-se de tuas próprias paixões, escreve G. Friedmann). Cada escola tem seu método terapêutico próprio, mas todas ligam a terapêutica a uma transformação profunda da maneira de ver e de ser do indivíduo. Os exercícios espirituais terão precisamente como objetivo a realização dessa transformação (HADOT, 2014, p. 22-23).

Os estoicos são efetivamente um exemplo concreto dessa terapêutica das paixões pelos exercícios espirituais, ao proporem evitar acontecimentos que não estão ao seu alcance determinar, e pelos quais eles devem educar-se para aceitar. Nos Exercícios Espirituais ao discorrer sobre o estoicismo Hadot coloca: "tomemos primeiramente o exemplo dos estoicos. Para eles, toda a infelicidade dos homens provém de buscarem alcançar ou manter bens que correm o risco de não obter ou perder [...] a filosofia vai então educar o homem para que busque alcançar apenas o bem que pode obter e busque evitar apenas o mal que se pode evitar" ${ }^{\prime 1}$. E no capítulo 7 do livro $O$ que é a Filosofia Antiga? Dedicado as escolas helenísticas, ratifica sua tese sobre os estoicos:

A escolha estoica opõe-se igualmente à escolha platônica, na medida em que pretende que a felicidade, isto é, o bem moral, seja acessível a todos.

A experiência estoica consiste em uma tomada de consciência aguda da situação trágica do homem condicionado pelo destino. Aparentemente não somos livres para nada, pois não depende absolutamente de nós ser belos, fortes, com boa saúde, ricos, experimentar o prazer ou escapar ao sofrimento. Tudo isso depende de causas exteriores a nós. Uma necessidade inexorável, indiferente ao nosso interesse individual, destrói aspirações e esperanças; estamos entregues sem defesa aos acidentes da vida, aos reverses da fortuna, à doença, à morte. Tudo em nossa vida nos escapa. Disso resulta que os homens são infelizes, porquanto procuram com paixão adquirir os bens que não podem obter e fugir dos males que são, contudo, inevitáveis (HADOT, 1999, p. 188).

O aspecto terapêutico dos exercícios espirituais buscava agir sobre as paixões, sobre nós mesmos, pois as outras coisas estavam além da nossa vontade. Agindo sobre nós mesmos os valores bem e mal estão equiparados ao bem e ao mal ético, pois são dependentes de nossas escolhas, enquanto o restante não depende de nossa liberdade de escolha. Eles levariam à vontade de fazer o bem e agir de acordo com a razão. O alcance desse modo de agir constitui um lento e árduo aprendizado de vida. Seria esta vigilância constante, o que permite estar sempre alerta e recorrer ao discernimento entre aquilo que depende de nós e o que não podemos determinar. Em última instância a filosofia era, para os estoicos, um modo de vida, e os

\footnotetext{
${ }^{15}$ HADOT, p. 23.

Perspectivas - Revista do Programa de Pós-Graduação em Filosofia da UFT - volume 5, n. 1 - 2020
} 
exercícios espirituais era praticar esse modo de viver livre e consciente. Consciente, no sentido de uma transcendência na própria individualidade, e livre por não desejar o que está fora do alcance determinar, levando a uma percepção de si como parte do cosmo racional, do todo racional. Essa característica da filosofia espalha-se pelas escolas helenísticas e romanas, deixando de ser uma atividade restrita as escolas e círculos filosóficos para se tronar uma prática social e um modo de vida. ${ }^{16}$

Essa filosofia como modo de vida inicia-se com Sócrates, no personagem idealizado por Platão a partir do Banquete. Essa opção pelo personagem idealizado por Platão em detrimento do Sócrates histórico é problematizada por Vlastos. Apresar da ligação estreita entre ambos os personagens, o Sócrates histórico, marcadamente é o personagem dos diálogos da juventude e o Sócrates idealizado é marcadamente o personagem dos diálogos maduros de Platão. Esse problema levantado por Vlastos poderia ser questionado por Hadot haja vista que não há diálogos socráticos, mas sim diálogos de Platão. Logo, a distinção apresentada por Vlastos entre o Sócrates dos diálogos da juventude e Sócrates dos diálogos maduros pareceria inverossímil, especialmente diante da interpretação de Pierre Hadot, para quem Platão, todo ele, é e continua sendo socrático, que portanto não há qualquer diferença abrupta, mas mudanças sutis, entre o personagem dos diálogos de juventude e de maturidade: "descobrimos, assim, outros aspecto capital da nova definição que Platão propôs no Banquete e que marcará de maneira definitiva a vida filosófica da Antiguidade" (HADOT, 1999, p. 91). Somente o quotidiano de Sócrates permite entender sua filosofia, e aí se revela sua exigência moral, seu estar fora do mundo e no mundo ao mesmo tempo. Ele representa o modelo ideal do filósofo por toda a antiguidade depois dele.

\section{Referências}

HADOT, Pierre. O que é a filosofia Antiga? São Paulo: Edições Loyola, 1999.

16 Segundo Cassiana Stephan: "talvez possamos afirmar que, segundo Hadot, o processo cultural de universalização dos preceitos da filosofia helenístico-romana se fundamentaria na atitude universal referente aos exercícios espirituais, pois o desenvolvimento da razão universal passou a ser uma tarefa destinada a todos os homens, independentemente de suas funções ou posições na sociedade. Por consequência, podemos admitir que a Universalização dos preceitos filosóficos, os quais prescrevem a sabedoria e a felicidade, concerniria nesse período a um processo histórico extremamente positivo à humanidade, pois ele desencadearia o gradativo esfacelamento das divergências sócio-políticas através da compreensão da relevância ontológica e moral da escolha por um modo de vida virtuoso. No período clássico a igualdade era concernente à distribuição proporcional e eficaz das funções a serem exercidas virtualmente em certa idade. Mas, precisamente, a igualdade detinha uma dimensão política que se conquistava por meio das atribuições advindas de um bom governante e da aplicação sensata das leis que vigoravam na pólis, ou seja, o exercício da igualdade se atrelava aos liames de determinada pátria". (STHEFAN, 2015, p. 97-98).

Perspectivas - Revista do Programa de Pós-Graduação em Filosofia da UFT - volume 5, n. 1 - 2020 
. Exercícios Espirituais e Filosofia Antiga. Tradução de Flavio Fontinelle Loque \&

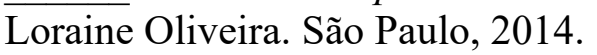

(1977). Exercices Spirituels. Annuaire de la $V^{\circ}$ section: Résumé des conférences et

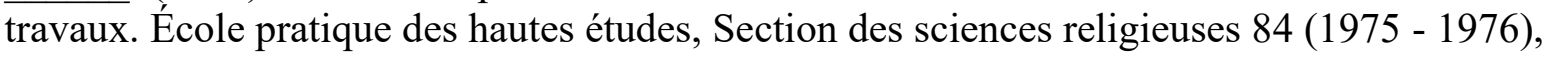
Paris: Imprimerie Nationale, p. 25-70.

. Elogio de Sócrates. Tradução de Flavio Fontenelle Loque e Loraine Oliveira. São Paulo: Edições Loyola, 2012a.

Elogio da Filosofia Antiga. Tradução de Flavio Fontenelle Loque e Loraine Oliveira. São Paulo: Edições Loyola, 2012b.

. A filosofia como maneira de viver: entrevistas de Jeannie Carlier e Arnold I. Davidson / Pierre Hadot. Tradução de Lara Christina de Malimpensa. - I. ed. São Paulo: É Realizações, 2016.

. (1995). Qu'est-ce que la Philosophie Antique? Éditions Gallimard, Paris.

. (2001). La Philosophie comme Manière de Vivre: Entretiens avec Jeannie Carlier et Arnold I. Davidson. Paris: Albin Michel.

. (2002). Exercices Spirituels et Philosophie Antique. Nouvelle edition revue et augmentée. Paris: Albin Michel.

. (2006) O Véu de Ísis: Ensaio sobre a história da ideia de natureza. Tradução de Mariana Sérvulo. São Paulo: Loyola.

(2008) N'oublie pas de Vivre: Goethe et la tradition des exercises spirituels. Paris:

Albin Michel.

ORTEGA, Francisco. Amizade e Estética da Existência em Michel Foucault. Rio de Janeiro: Graal, 1999.

PLATÃO. Diálogos: Fedro, Cartas, O Primeiro Alcibíades/ Platão. Tradução de Carlos Alberto Nunes, Pará: EDUFPA, 2007.

. O Banquete. Tradução de Carlos Alberto Nunes, Pará: EDUFPA, 2011.

Apologie de Socrates. 17d. Tradução de M. Croiset. Paris: Les Belles Lettres, 1970.

Lettres, 1929.

Alcibiades. In: Oeuvres complètes. Tradução de M. Croiset. Paris: Les Belles

La Répuplique. Tradução de E. Chambry. Paris: Les Belles Lettres, 1934.

STEPHAN, Cassiana Lopes. Michel Foucault e Pierre Hadot: um diálogo contemporâneo sobre a concepção estoica do si mesmo. Cassiana Lopes Stephan. - 2015. 
TESTA, Federico. Hacia una historia de las prácticas filosóficas en Michel Foucault y Pierre Hadot. Traduccion de Patricia Salome. Konvergencias, Filosofía y Culturas en Diálogo, Número 24, abril 2017, p. 179-199.

VLASTOS, G. Socrates, ironist and moral philosopher. Itarca/New York: Cornell University Press, 1991. (Col. Cornell Studies in Classical Philosophy, v. 50). 